Names for these various devices seem for purposes of reference necessary, and I would propose calling the following two postures aphelic ( $\left(\dot{a} \pi \dot{d} \check{c}^{\prime \prime} \lambda \iota \xi\right)$ positions.

The first is to be done, according to severity and bodily vigour, once, twice, or even three times a-day, of course not nude, but divested of any even slightly stiff corset. The annexed photograph from the patient, depicted in Fig. 4 of



Fig 8.-First aphellc positıon.

my first paper, was thus taken; she was lying on a rug upon the floor; on a slight scaffold erected above her was a hole in the plankage vertically above her hip; the camera, lens downward, was placed over this hole, through which the birdseye view of the recumbent figure was with some difficulty obtained. To rightly assume this posture, the patient is to lie on her left side, draw up the knees so that the thighs are at about a right angle with the trunk, and is especially to see that the right knee does not project further forward than the left one (herein the figure is a little wrong), thus ensuring against the pelvis rolling over to the front; she then so twists her chest and shoulders that those parts lie as much as possible on their front aspect. At first sight, it might be supposed that this would increase the left torsion at the loin, but in practice this is found not to be the case ; the twist caused by the position does not extend below the tenth dorsal vertebra; yet, when a left convex lumbar curve is strongly marked, I place a short rather protuberant cushion on that side, immediately above the iliac crest. If the patient have a pretty plainlymarked consecutive cervical curvature, which of course must be to the left, she is not to put her head in the position shown in the figure, but is so to turn it that it lies on the left cheek; this is a little, but only a little, more exacting. Certain patients ean go to sleep at night, at all events for a time, with the body twisted as above depicted; others, and this seems to depend partly on more or less irritability of the heart and of the digestive organs, cannot do so. These, however, especially if young and flexible, are generally able to fall asleep in the second position, as here shown. The twist, or rather the untwist, of the spine is the same; but the patient lying on her right side rolls the upper part of the figure over, so that it lies as much as pos sible on the back. This is less potent than the first position, but if the patient can fall thus quietly to sleep, it is in mere gain of time a valuable addition.

It is impossible for anyone, until he has employed this method, to form any idea of the changes in form immediately produced by this position; nor would I believe them until I had verified them on a great number of patients. Moderate right convex curves as a rule become straight, or even deflected in the opposite direction; the backward p ojecting right ribs no longer form, together with the scapula, a projection, but rather a wide shallow depression, while the flattened, perhaps even hollow, left shoulder rounds itself out almost to its proper form. One category of patients, however, resist these benefits - namely, those whose unfortunate backs have been stiffened by the use of iron cages (spinal supports), but this recalcitrance can be pretty quickly overcome by directing a nurse or other attendant, while the girl is in the first position, to press with her hands the protruding right shoulder down towards the couch or floor on which she lies. The first essential of any rational treatment must be to eliminate this artificial stiffness, which of course quite prevents the natural and salutary play of muscles.

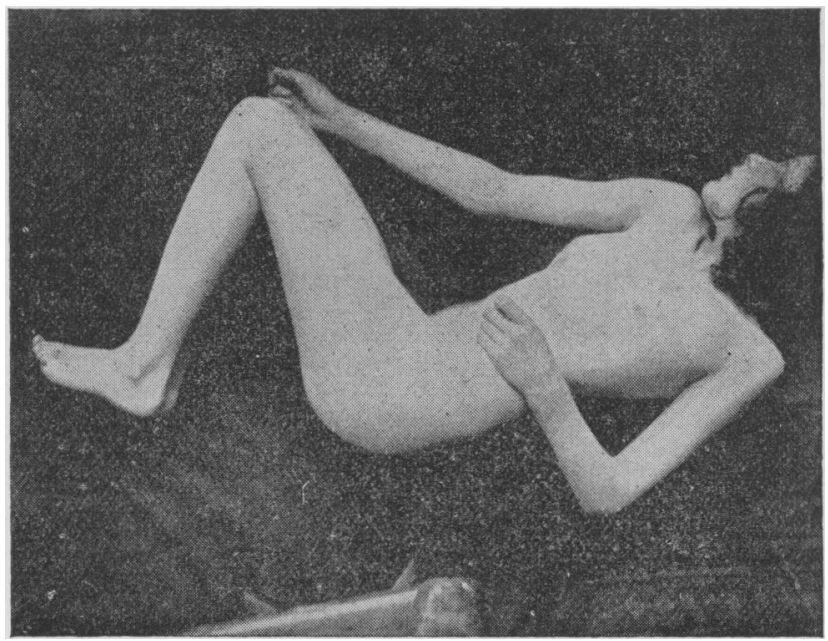

Fig. 9.-Second aphelic position.

In 1887 the Clinical Society nominated a Committee to consider the "question of lateral curvature of the spine," and in the following year its Report was published, ${ }^{4}$ which, although somewhat vague, indicates pretty clearly that the Committee considered "the various methods of treatment at present in vogue" yielded unsatisfactory results-a conclusion which, unless it couid be refuted, points to a serious defect or blemisl in this department of surgery. Imbued with the feeling that the belief of the Committee could not be altogether repudiated, I set myself to investigate the conditions which even in moderate cases are obstacles to cure. In the course of this work I soon observed the till then undetected deviations of the pelvis (amesiality and version), not merely coexisting with but preceding and inducing lateral curvature. From this point the next step is inevitable, namely, that in order to cure a spine, crooked because its foundation is awry, we must eliminate the sidewass slant or twist of that basis. It being self-evidently useless, even if it were possible, to straighten by gymnastics of whatever nationality, by iron cages, by violent manual pressure, or by any other means, a spine which, according to the simple laws of balance and gravitation, cannot by any possibility stand straight upon a foundation whose one-sidedness or twists have been overlooked and neglected. It is this gap in our knowledge (hitherto) of lateral curvature which has led to the stigma that the Clinical Society's Committee pointed out, and which the writer believes these three short communications will permanently remove.

NOTE AND REFERENCES.

1 Hysterical spinal curvature, a not infrequent addition to this particular pelvic deviation, must be excepted 2 BRITISH MEDICAL JOURNAL, January, 21st, ison, 3 The Causs and Treatment of Lateral Curvature, 1895 4 Clinical Society's Transactions, vol. xxi, p. зоr.

\section{THE INTERPRETATION OF SKIAGRAPHS.}

By E. MUIRHEAD LITTLE, F.R C.S.Eng., Surgeon to the National Orthopædic Hospital.

THE interpretation of skiagraphs is somewhat difficult, partl y because structures familiar enough in the dissecting room a 10 portrayed in unfamiliar relations, and partly because it is $\mathrm{n}$ ot always borne in mind that the image produced is practical ]y a shadow, and subject to the same distorting influences a s shadows. The less the ratio between the distance of the bon $e$ from the sensitised plate, or fluorescent screen, and the dis- 
tance of the focus tube from the same, the more is the shadow enlarged; and the nearer the bone to the plate the sharper the outline of the shadow. The aim of the skiagrapher, therefore, is to get the bone as near to, and the tube as far from, the plate as may be. In practice, however, so much power is lost by removing the tube to a distance that in skiagraphing dense and thick parts it is generally kept near, and sharpness has to be sacrificed, to some extent, to penetration.

In no part of the body are mistakes more likely to be make than in considering skiagraphs of the pelvis and hips. At the Congress of the German Society of Surgery at Berlin in April, 1898, Hofmeister showed a number of skiagraphs of oule normal pelvis from various points of view which gave various false appearances of deformity of the pelvis and femurs. It is, however, not necessary to go to the trouble of producing $x$ rays and to the expense of large plates in order to show the form of the images which would be produced in various relative positions of focus tube, skeleton, and plate. Exactly similar images may be produced by means of a small lamp, the bones in question, and a sheet of paper. In this way the shadows from which the annexed illustration was photographed (with the exception of $A$ ) were produced. They were all taken from the same normal left femur of an adult; $A$ is from an outline of the upper end of the bone which was laid with the posterior surface of its head and its lesser trochanter resting on the paper. To insure accuracy, the pencil was held in the pencil-holder which was described in the Lancet of April 29th, 1893.

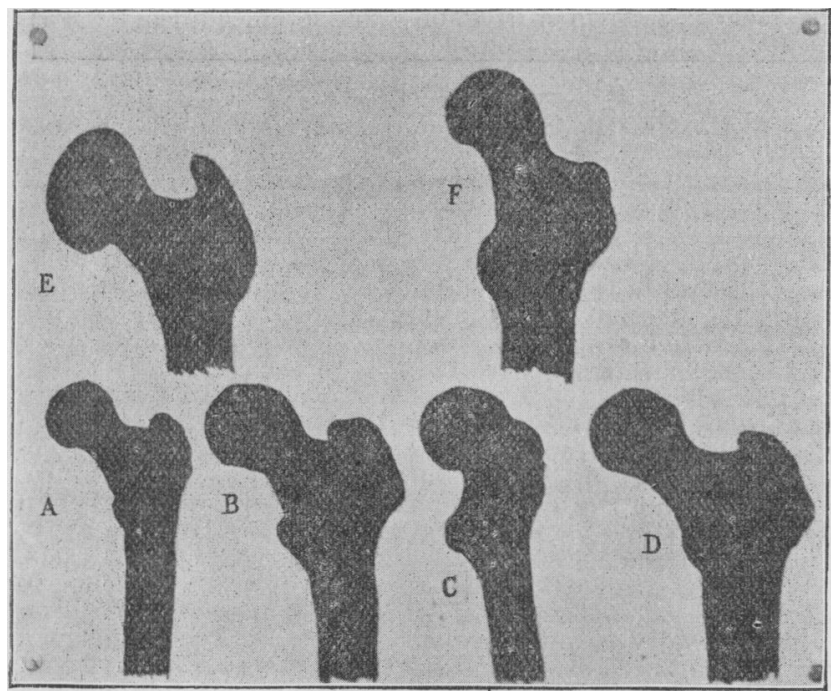

Fig. x.-Sluadows of upper end of femur, left ; $\mathbf{A}$, Outline (actual size) filled in ; B, Not rotated; C, Kotated out about 40 degrees ; D, Rotated in about 30 degrees ; E, Light over a point of body 9 hyperextensions); $F$, Flexed about 45 degrees.

In $\mathbf{B}, \mathbf{C}, \mathbf{D}$, and $\mathbf{F}$ the relative positions of light, femur, and paper were such as would probably occur in skiagraphing an adult pelvis when, as is usually the case, shadows of both hips are desired for purposes of comparison. In such a case the tube is usually placed over the middle line, between the hip-joints, and at a variable distance from the plate, which may fairly be estimated as 12 inches, the plate lying under the supine body of the patient. The most posterior part of the head of the femur would in a well-developed adult be about 3 inches or more from the plate. The shaft of the femur from which these shadows were formed was therefore held vertically in a tule-holder, the nearest part of the head of the bone being 3 inches from the paper. The light was placed 3 inches horizontally inwards from the innermost part of the head of the femur-this may be assumed to be about the average distance of the bottom of the acetabulum from the middle line-and 12 inches from the surface of the paper. The paper itself was in all cases fixed flat against a wall. The resulting shadows were outlined with a pencil and afterwards blacked in before they were phatographed. The shadows resemble the images that would be seen on looking at the plate with the film surface towards one.

In $B$ the bone was neither rotated in nor out. A comparison with A shows it to be enlarged, as all the shadows are, and slightly distorted owing to the obliquity of direction of the rays casting the shadow. In $\mathrm{c}$ the femur was rotated outwards about 40 degrees. The neck appears much shortened, and the angle between it and the shaft much increased. A similar appearance is very often seen in skiagraphs. In $\mathrm{D}$ the femur was rotated inwards about 30 degrees. In $F$ it was not rotated, but inclined as if flexed 45 degrees. In $\mathrm{E}$ the bone and paper were in the same relative positions as in $B$, but the light was moved upwards and outwards, so that it was 9 inches above the head of the femur, and Io inches horizontally from the plane of the paper. This corresponds to a position about over the eighth costal cartilage in the nipple line.

In the paper above mentioned, Hofmeister stated that the angle of the neck with the shaft of the normal femur might be made to appear as small as 90 degrees by alterations of the relative positions of light, plate, and skeleton. The shadow shown at $\mathrm{E}$, however, is the nearest approach to such an appearance that could, I think, be unintentionally produced by even the most careless or inexperienced skiagrapher. It is easy to test the truth of the above statements in five minutes with the help of a night light (or other small bright source of light) a femur, and a sheet of white paper pinned against the wall.

A point of interest in skiagraphs of the pelvis in children is the evidence of the presence of the $Y$-shaped cartilage in the acetabulum, which shows in a print as a clear space. This marks the position of the cotyloid cavity, and it will be seen that the head of the femur when normally in joint lies almost entirely below this cartilage.

Hofmeister has pointed out that in skiagraphing both hips with a view to obtain information as to the angle between neck and shaft, if the patient be supine with the plate underneath him, the thighs should be rotated inwards in order to obtain a result that will not mislead. Even thus the shadow will be somewhat distorted (see $D$ in figure), for although the plane of the head and neck may be at right angles to the path of the rays, the dry plate will be oblique. Moreover, in coxa vara rotation inwards is often impossible, and the limb strongly rotated outwards. In such a case it would seem to be better to skiagraph each hip separately, with the patient prone or supine as seems most convenient, placing the tube so that the rays shall pass perpendicularly to the posterior or anterior surface of the neck, and placing the plate as nearly as possible parallel to that surface.

\section{REMARKS ON LARYNGEAL GROWTHS IN YOUNG CHILDREN.}

Being the concluding portion of a Post-Graduate Address at the Eye, Ear, and Throat Infirmary, Edinburgh.

By G. HUNTER MACKENZIE, M.D.

THE subject of laryngeal"growths in young children is one to which I wish next to direct your attention, because in the first place the complaint is not uncommon, and secondly on account of the line of treatment which $I$ intend to recommend to you being alike different and simpler from that usually followed. I am fortunately able to present to you a case upon which, in the first place at least, my remarks will be based.

The patient, a girl aged 17 months, has suffered from increasing huskiness for about one year. From the date of birth until she was from 4 to months old, she is represented as having a perfectly clear voice; of this lier parents have no doubt. At this age, and apparently without any

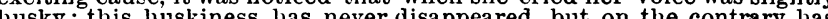
husk, this liuskiness has never disappeared, but on the contrary has row tho that some respiratory stridor can be detected, not so much when the child is quitat and at rest ans the suffered from serious illness.

Such, in short, is the history of the case. What are the conditions giving rise to these symptoms, and how can they be diagnosed? In a child of such tender age as the one now before you I do not think it necessary to make use of direct or indirect laryngoscopy, which in either case would require, 